\title{
ORAL HEALTH OF EPILEPTIC PATIENTS IN RURAL RAJASTHAN
}

\author{
Rakshit Sureka1, Jyoti Paliwal' ${ }^{2}$ Tahir Mohd. ${ }^{3}$, R. K. Sureka ${ }^{4}$ \\ ${ }^{1}$ Senior Resident, Government Dental College, Jaipur. \\ ${ }^{2}$ Professor, Department of Prosthodontics, Government Dental College, Jaipur. \\ ${ }^{3}$ Assistant Professor, Department of Prosthodontics, Government Dental College, Jaipur. \\ ${ }^{4}$ Ex-Professor, Department of Neurology, SMS Medical College.
}

\begin{abstract}
BACKGROUND: Despite the increase in the awareness of Epilepsy, still people are not much aware of the oral health complications related to the intake of antiepileptic drugs.

OBJECTIVE: To assess the most common oral health problems that people face while using the Anti-epileptic drugs and hence forth decide its remedy. To make people aware of the potential side effects of using the anti-epileptic drugs.

MATERIALS AND METHODS: This study was conducted on 200 epileptic patients who were on anti-epileptic medication for one year or more. The study was conducted at Government Hospital in Ratan nagar dist churu.

RESULTS: Gingival hyperplasia was seen as a common side effects of the Anti-epileptic Drug. Lips and cheek biting were the most common soft tissue injury, while tooth fracture was the most common hard tissue dental injury.

CONCLUSION: General physicians and dentist should be well aware of the potential side effects of Anti-epileptic Drugs. A dentist should be well versed and trained to manage oro-facial injuries in the emergency department.
\end{abstract}

KEYWORDS: Anti Epileptic Drugs, Epilepsy, Gingival Hyperplasia, Phenytoin Sodium and Seizures.

HOW TO CITE THIS ARTICLE: Rakshit Sureka, Jyoti Paliwal, Tahir Mohd., R. K. Sureka. "Oral Health of Epileptic Patients in Rural Rajasthan". Journal of Evolution of Medical and Dental Sciences 2015; Vol. 4, Issue 88, November 02; Page: 15367-15369, DOI: $10.14260 /$ jemds/2015/2187.

INTRODUCTION: Epilepsy is a major health problem in both developed and developing countries. Different Indian studies including a recent meta-analysis determined prevalence around 5 to 6 per 1000 population and incidence around 38 to 49.3 per 100,000 population. ${ }^{1}$ A prevalence of 5 per 1000 population translates into 5 million patients in India at any given time.

Epilepsy is thought to affect millions of people worldwide, and has a prevalence of $0.5 \%-0.9 \%$ in the general population. ${ }^{2}$ It has been reported that the disease occurs independent of race, age and gender. However, epilepsy occur more frequently in men than in women. Epilepsy has been observed most frequently in children under 1 year of age and in people over the age of 75.3

In $70 \%$ of epilepsy cases, the specific etiololgy is not known for certain. These cases are defined as idiopathic or primary epilepsy. When the etiology of seizures is known, the condition is known as secondary or acquired Epilepsy. Other causes of epilepsy are cerebral vascular malformation, brain tumors, hamartomas, head traumas, infection etc.

Epilepsy is classified according to seizure type: generalized type, partial type and status epilepticus.

Epilepsy is a disease that is frequently encountered by oral and maxillofacial surgery practices. ${ }^{4}$

Financial or Other, Competing Interest: None.

Submission 08-10-2015, Peer Review 09-10-2015,

Acceptance 20-10-2015, Published 02-11-2015.

Corresponding Author:

Dr. Rakshit Sureka

\#47, Sanjay Marg Hathori Scheme Jaipur,

Jaipur-302001, Rajasthan.

E-mail: rsureka@rediffmail.com

DOI: $10.14260 /$ jemds $/ 2015 / 2187$.
Initially single AED was used to manage epilepsy but nowadays a combined regimen is used there by making the treatment intricate and ensuring better results. The classical AED are Phenytoin, Phenobarbitone, Sodium Valporate, Carbamazepine. The overall oral health status of epileptic patients is poor than the healthy individuals. Further more the oral health worsens with the severity of epilepsy.

MATERIALS AND METHOD: The study was conducted on 200 patients over a period of Six months which came in the free epilepsy camp conducted at Government hospital in Ratannagar, dist Churu by neurologist author who is running a free epilepsy camp since 21 years.

All the patients taken were known cases of epilepsy and were under antiepileptic medication for at least 1 year. Epileptic patients who were currently not taking any medication or had started medication less than a year before were excluded from the study. Informed consent was taken from patients/guardians. The patients were examined by the dentists and neurologist.

RESULTS: After completing the study, we came to the following results:

Table 1: shows the age group of patients who participated in the study. In the study $25 \%$ of patients were children between age group of 5-15 years of age. This shows that epilepsy is very much prevalent among children. Rest $25 \%$ and $30 \%$ were between age group of 25-35 years and above 35 years of age.

Table 2: Shows the causes of epilepsy in which most of the causes were cryptogenic (60\%) few were due to infections $(10 \%)$, tumours $(7.5 \%)$ and very rarely due to cortical atrophy $(2.5 \%)$. 
Table 3: Shows antiepileptic drug regimen in which majority of patients were on dual therapy (50\%) including Phenytoin sodium + Phenobarbitone. Few of them were on mono therapy (30\%) including Phenytoin Sodium. Very few cases were on three drug and four drug therapy $(15 \%$ and $5 \%$ respectively).

Table 4: shows the side effects of Antiepileptic drugs. In which gingival hyperplasia was seen as the most common side effect of the drugs used (75\% of cases), gingivitis was seen as the second most common (15\%) and very few cases were reported of xerostomia and stomatitis $(7.5 \%$ ad $2.5 \%$ respectively).

Table 5: Shows all the common side effects of drugs used in the study.

Table 6: Shows the dentofacial injuies that a patient can encounter during the seizure. Lip/Cheek biting was the most common injury which occurred (59.5\%) of patients. Tongue injury including tongue biting was the second most common injury (35.5\%), very rarely tooth fracture occurred (5\%).

Table 7: Shows the assessment of TMJ injuries that occurred during the attack. Many patients encountered tenderness (16.5\%) in the TMJ area. In few of the patients clicking sound was also present (9\%) and in few of the patients subluxation (4.5\%) was there.

DISCUSSION: During seizures, injuries such as soft tissue damage, tongue injuries, fractures within the maxillofacial region, temporomandibular joint subluxations, tooth fractures, subluxation or avulsion frequently occurs.

In the study large amount of patients were children between age group 5-15 yrs. and $30 \%$ of them were between age group above 35 yrs. of age.

Gingival hyperplasia was seen as a common side effects of AED drugs in $75 \%$ of patients. Presently the etiology of drug induced gingival overgrowth is not clear but it is multifactorial. Also the effect of age, sex, duration and dosage of the drug in the pathogenesis of gingival overgrowth is not clearly understood. ${ }^{5}$

A positive correlation was found between decreased level of serum folate and increasing severity of gingival enlargement due to consumption of AED. They concluded that reduced serum folate level can even lead to early onset of oral side effects. ${ }^{6}$ Cheek biting was seen as most common injury (59.5 \%) in the population studied. Few studies have reported that epileptic seizures lead to moderate to severe injuries. The main reason for an epileptic attack was that the patient was not following the drug regimen properly. ${ }^{7}$ retrospective study of TMJ dislocation the most common disease came out to be Epilepsy.

In the study most of the patients were on dual therapy (50\%) and some of them were on monotherapy (30\%), few were on three drug and four drug therapy. Research indicates that epileptic patients have severely inadequate mouth hygiene, oral health and dental condition as compared with nonepileptic patients.

The newer antiepileptic drugs produce oral manifestations only infrequently. Xerostomia and stomatitis have been reported rarely as a side effects of Carbamazepine. ${ }^{8}$ and rash that may involve the oral cavity has been associated with lamotrigine and can be exacerbated by the concomitant use of valproic acid.
Valproic acid can cause direct bone marrow suppression, which can impair wound healing and increase post-operative bleeding and infections. Decreased platelet count is the most common and best recognized hematologic effect of valproic acid; the incidence varies from $5 \%$ to $40 \%$. Clinically significant bleeding is uncommon because the thrombocytopenia is usually not severe. For elective surgery, laboratory evaluationincluding bleeding time, fibrinogen level, prothrombin time, partial thrombplastin time and von Willebrand factor level- is needed to assess the risk of peri- and postoperative bleeding. Bleeding as a potential side effect should be discussed with patients and their families in preparation for surgery. ${ }^{9}$

In a recent analysis of the prosthdontic status of patients with epilepsy. ${ }^{10}$ it was found that compared with age-matched controls, patients with epilepsy have a tendency to become edentulous earlier. It was also found that prosthodontic treatment is suboptimal, as significantly fewer teeth are replaced, despite the fact that epileptic patients tend to have more missing teeth. Based on these findings, the authors suggested a classification for patients with epilepsy according to dental risk factors and dental manageability and provided recommendations for dental treatment.

The cost involved in the treatment of side effects has been found to affect the economy of the nation. The medical expenditure on the treatment of side effects was found to be an economic burden for the society. ${ }^{11}$

CONCLUSION: Overall quality of life, general and dental health is hampered by epilepsy. As a result of poor oral hygiene, dental trauma during seizures and the side effects of the medication for the epileptic patients. Tooth loss, caries and periodontal diseases is found more frequently in epilepsy sufferers than in non-sufferers. For that reason the epileptic patients need more dental treatment than the other patients.

\section{REFERENCES:}

1. Ray BK- Epidemiology of epilepsy- Indian perspective. Journal of Indian Med Association 2002; 100: 322-6.

2. M.D. Turner and R. S Glickman, "Epilepsy in the oral and Maxillofacial Patient: Current therapy" Journal of Oral and Maxillofacial Surgery, vol. 63, no 7, 2005: 996-1005.

3. G.V. Busschots and B.I. Milzman, "Dental Patients with neurologic and Psychiatric Concerns, "Dental clinics of North America, vol. 43, 1999: 471-483.

4. Yalturuk Mehmet et al. "Management of Epileptic Patients in dentistry" Surgical Science, 2012, 3, 47-52.

5. A Gautam, PK Verma, R Srivastava, K Lodhi. "Esthetic correction of Phenytoin induced gingival hyperplasia- case reports health care 2013; 1 : 28-31.

6. NA Singh et al. "Phenytoin, Folic acid and gingival enlargement: breaking myths". Contemporary clin dent. 2014; 5(1), 59-66.

7. J. Saengswan et al. "Integrated epilepsy research group. Seizure related vehicular crashes and falls with injuries for people with epilepsy in north eastern Thailand. Epilepsy behaviour, 2014; 32:49-54.

8. Li LM Et al. Allergic skin rash with lamotrigine and concomitant valproate therapy: evidence for an increased risk. Arq Neuropsiquiatr 1996; 54 (1); 47-9.

9. Archarya S, Bussel JB. Hematologic toxicity of Sodium valporate. Pediatr hemat oncol 2000; 22(1); 62-5. 
10. Karolyhazy K, Kivovics et al. Prosthodontic status and recommended care of patients with epilepsy. J Prosthet Dent 2005; 93 (2); 177-82.
11. R.J. de Kinderan et al. Side effects of Antiepileptic drugs. The economic burden; Seizure 2014; 23 (3); 184-190.

\begin{tabular}{|c|c|c|}
\hline AGE GROUP (YEARS) & N & PERCENTAGE \\
\hline $0-5$ & 20 & 10 \\
\hline $5-15$ & 50 & 25 \\
\hline $15-25$ & 20 & 10 \\
\hline $25-35$ & 50 & 25 \\
\hline ABOVE 35 YRS ONWARDS & 60 & 30 \\
\hline Table 1: Table Showing Different Age Groups of Patients with Epilepsy \\
\hline
\end{tabular}

\begin{tabular}{|c|c|c|}
\hline ETIOLOGY & N & PERCENTAGE \\
\hline IDIOPATHIC & 20 & 10 \\
\hline CRYPTOGENIC & 120 & 60 \\
\hline TUMOR & 15 & 7.5 \\
\hline ARTERIOVENOUS MALFORMATION & 10 & 5 \\
\hline CORTICAL ATROPHY & 5 & 2.5 \\
\hline INFECTION & 20 & 10 \\
\hline OTHERS & 10 & 5 \\
\hline Table 2: Causes of Epileptic Seizures \\
\hline
\end{tabular}

\begin{tabular}{|c|c|c|}
\hline AED DRUG REGIMEN & N & PERCENTAGE \\
\hline MONO THERAPY & 60 & 30 \\
\hline DUAL THERAPY & 100 & 50 \\
\hline THREE DRUG & 30 & 15 \\
\hline FOUR DRUG & 10 & 5 \\
\hline \multicolumn{2}{|c|}{ Table 3: Antiepileptic Drug Regimen Consumed By Patient } \\
\hline
\end{tabular}

\begin{tabular}{|c|c|c|}
\hline ORAL SIDE EFFECTS OF AED & $\mathbf{N}$ & PERCENTAGE \\
\hline GINGIVAL HYPERPLASIA & 150 & 75 \\
\hline GINGIVITIS & 30 & 15 \\
\hline XEROSTOMIA & 15 & 7.5 \\
\hline GLOSSITIS/STOMATITIS & 5 & 2.5 \\
\hline
\end{tabular}

\begin{tabular}{|c|c|c|}
\hline MEDICATIONS & INDICATION & SIDE EFFECTS \\
\hline PHENOBARBTONE & $\begin{array}{c}\text { Partial and Secondary } \\
\text { generalized seizures }\end{array}$ & $\begin{array}{c}\text { Drowsiness/sedation, } \\
\text { osteopenia/osteomalacia }\end{array}$ \\
\hline CARBAMAZEPINE & $\begin{array}{c}\text { Partial and Secondary } \\
\text { generalized seizures }\end{array}$ & $\begin{array}{c}\text { Xerostomia, stomatitis, } \\
\text { gingival bleeding, rash }\end{array}$ \\
\hline PHENYTOIN & $\begin{array}{c}\text { Partial and Secondary } \\
\text { Generalized }\end{array}$ & $\begin{array}{c}\text { Gingival hyperplasia, } \\
\text { gingival bleeding }\end{array}$ \\
\hline SODIUM & Partial and generalized & $\begin{array}{c}\text { Gingival bleeding, } \\
\text { petechiae, decreased } \\
\text { platelet count }\end{array}$ \\
\hline LALPORATE & Partial and generalized & Rash \\
\hline OXCARBAZEPINE & $\begin{array}{c}\text { Partial and Secondarily } \\
\text { generalized }\end{array}$ & Unknown \\
\hline LEVETIRACETAM & Partial and generalized & Unknown \\
\hline \multicolumn{2}{|c|}{ Table 5: Medications and Side Effects of Medications Used in the } \\
\hline
\end{tabular}

\begin{tabular}{|c|c|c|}
\hline TRAUMATIC INJURIES & N & PERCENTAGE \\
\hline LIP/CHEEK BITING & 119 & 59.5 \\
\hline TONGUE INJURIES & 71 & 35.5 \\
\hline TOOTH FRACTURE & 10 & 5 \\
\hline \multicolumn{2}{|c|}{ Table 6: Dentofacial Traumatic Injuries in Epileptic Patients } \\
\hline
\end{tabular}

\begin{tabular}{|c|c|c|}
\hline TMJ ABNORMALITY & $\mathbf{N}$ & PERCENTAGE \\
\hline TENDERNESS & 33 & 16.5 \\
\hline CLICKING & 18 & 9 \\
\hline SUBLUXATION & 9 & 4.5 \\
\hline NORMAL & 140 & 70 \\
\hline \multicolumn{2}{|c|}{ Table 7: Assesment of TMJ Injuries In Epileptic Patients } \\
\hline
\end{tabular}

